\title{
CHINA'S RECENT RESEARCH WORK ON PSYCHOLOGY
}

\author{
PAN SHUH \\ Institute of Psycholog $\gamma$, Academia Sinica, Peking
}

Since the Liberation, psychologists in China have been intensively studying Marxism as well as the Soviet psychology and Pavlov's theory. Profiting by the experience of Soviet psychologists in building up the dialectic Materialist Psychology, Chinese psychologists fully realized that, in order to shake off the ideological and methodological influence of the Idealistic Psychology of Capitalist countries, and in order for psychology to take up its share of important tasks in Socialist Reconstruction, it is necessary to reconstruct a scientific psychology upon the basis of Pavlov's theory in accordance with Marxist principles.

I

All these ten years, most Chinese psychological workers have proceeded along this correct path in building a dialectic Materialist Psychology. On the one hand, they have incessantly explored and criticized the various schools of Capitalist psychology, including James and Dewey's Pragmatism, which had a profound influence upon Chinese psychology, until the time of Liberation. On the other hand, they have started many investigations.

Of the new preliminary studies in psychology, most were undertaken in accordance with the Marxian materialistic interpretation of psychological phenomena and also with the objective principles in methodology. During the early period after the Liberation, one of the methods most frequently used was the Pavlov's conditioned reflex method. The major objective of these experimental studies was to explore the "material basis of psyche"--- the fundamental rules governing the activities of the brain as well as the physiological mechanisms which underlie certain psychological processes.

Preparing for an extensive research in genetic and developmental psychology, Chinese psychological workers started with the analysis of the animal's analytic and synthetic abilities and made a preliminary study of the methods of training the animals (dogs) to learn fine differentiation, and also the methods of investigating animal's simultaneous discrimination. The study of human psychological processes began with the exploration of the visual perception of movement. Adopting Pavlov's viewpoint, psychologists analyzed the condition contributing to the formation of the Phi-phenomenon, and proposed a preliminary hypothesis. In their opinion, the apparent movement may be due to the fact that in the cortex the spreading excitation of the first stimulus is attracted by the locus of excitation of the second stimulus. They disagree with the so-called "trancendental theory" of apparent movements presented by the Gestalt school. Having measured the threshold of visual perception of motion, they proceeded to study visual judgment of speed of motion and analyzed the effects of different conditions on estimating speeds of motion. In the field of auditory sensation, measurements of absolute auditory thresholds were undertaken on a quite large scale and with a rather high precision. This work is being coatinued. Regarding thinking prozesses, motor skills and personality, the experimental work done in the early period was mostly concerned with their physiological mechanisms. Experiments on mutual dynamic transposition of two signal systems served as a starting point in the study of thinking problems. They employed mainly the 
method of motor conditioned reflex with verbal reinforcements and used preschool and school children, adults, as well as psychotic patients as their subjects. Psychologists made preliminary investigations of the regulating role of words, fine discrimination, and the effects of conditional signals, rewards and age, etc., on selective generalization. For the purpose of revealing the physiological mechanisms of technical skill, an experimental investigation on the orderly response and motor dynamic stereotype was carried out. They had the opinion that the occurrence and the rebuilding up of orderly responses can be regarded as indices of reflexbility of higher nervous activities. These experiments did also facilitate further studies of problems about skill and technique.

To the Chinese psychological workers, experimental studies on characteristics of different types of higher nervous activity may be considered as a starting point in the investigation of personality and also as a part of the study of the psychological basis of personality. Starting with the experimental study on characteristics of different types of higher nervous activities in young dogs from the same litter, investigation with the collective running method was carried out and studies with the sound-proof room method was followed for the study of animal's types of higher nervous activities and the growth of the various types. For the study of the type characteristics of 'Bahnung' in children, psychologists used the method of motor conditioned reflex by means of verbal reinforcements and suggestions in sound-proof rooms. They believed that by using these methods, they could explore, to some extent, the degree of the equilibrium and the mobility in the 'Bahnung' of children. However, all these studies amount only to preliminary attempts, and further investigations are required.

In this period, not much work was carried out in connection with daily life practice, which might bring solution to practical problems. Although in the field of teaching, psychologists tried to help the instruction work in primary schools, and tried to investigate the development of children's personalities by analyzing their psychological characteristics, and although in the studies of industrial and medical psychology, psychologists also made some attempts to connect their researches with productive labor and the medical work, yet they failed to obtain any significant results worth of mention.

\section{II}

The above-mentioned is an account of the attempts of the Chinese psychologists in establishing the dialectic Materialist Psychology during the early period after the Liberation. One can easily see that their work was just at the beginning stage. Nevertheless, their work differed basically from what was done before the Liberation: they had been trying to do psychological researches on an entirely new theoretical basis.

In 1957, a nation-wide Rectification Movement was carried out throughout the country. When this Rectification and the first Five-Year Plan were brought to a victorious end, there came up a new phase, the so-called "big-leap" in all the industrial as well as the agricultural work. This had a profound influence on China's scientific researches of every field. The speedy developments in all aspects of China's Social Reconstruction also brought forth many new tasks and demands for psychology, and thus, China's psychological research entered into a new era. The main features of this period's work were the investigations of how to psychology serve the practical work in Socialistic Reconstruction, and how to speed up the con- 
struction of dialectic Materialist Psychology through solving practical problems. It should be recognized that the emphasis on connecting psychology with practice in this period does not imply the denial of Chinese psychologists' earlier work on fundamenal problems, but rather indicate further developments of these studies. However, in order to gain actual experience in practical work, they had to slow down some parts of the researches on psychological processes and their physiological mechanisms, which were done in the earlier period, and to concentrate more efforts on those studies closely related to practical problems.

Viewed from the present situation, the main works of Chinese psychologists in this new period can be summarized as follows.

Educational Psychology. As regards the educational psychology in comformity with the recent situation of "big-leap" in our country's education, part of psychological workers engaged themselves in the study of the grade-school enrollment age. Collaborating with the educational workers, they organized several experimental classes of 6-yr. old children and tested their suitability to the grade-school enrollment. In order to be able to offer some psychological principles concerning this schooling age problem, they first investigated the age differences between 6 and 7-yr. old children in getting various knowledges, especially language and arithmetic, and then compared the age characteristics of 6 and 7-yr. old children in perception, attention, memory, and understanding ability, etc. which are involved in children's learning processes.

With a mind to improve the efficiency of teaching, some psychologists conducted a study on children's learning of the applications of the "four rules of arithmetic." Breaking away from the old system of teaching grade-school arithmetic, they prepared lessons themselves in accordance with the characteristics of children's thought processes. Moreover, experiments were done on giving the 5th-grade students the instruction of the basic knowledge of algebra which was used to solve the practical problems concerning the "four rules of arithmetic." Results of this study suggested a possible way of improving the lessons of the gradeschool arithmetic, teaching methods as well as the allocation of the time for learning.

As for the thorough application of the principle of combining education with productive labor, some psychologists are now concerned with psychological problems about students who take part in productive labor, some others are investigating ways of combining school courses (e.g. physics) with productive labor so as to intensify the effects of teaching and also to facilitate the development of students' intellectual abilities. Chinese psychologists regard accelerating the cultivation of students' Communist thinking and character as one of the important tasks which is closely related with psychological work. In this connection, some psychological workers have studied the role of collective boarding and rooming systems in schools, which was put in trial practice since the "big-leap" following the establishment of the People's Communes, in evolving the spirit of Collectivism. From social practice, they have tried to analyze and study the factors favoring the development of Communist thinking and character with a mind to suggesting effective ways of cultivation.

Industrial Psychology. Just as the "big-leap" in educational work promoted the development of researches concerning educational psychology, the "big-leap" in our country's industry and agriculture likewise offered a broad future for the development of industrial psychology. In 
order to serve industrial production by increasing labor efficiency, Chinese psychologists studied methods of improving operation. Applying to punch-workers the method of analysis of the operational movements, they investigated the principles of rational operations such as pre-localization by means of visual and tactile sensations, ambidextrous coordination in operations, as well as elimination of superfluous movement. This way they helped factories in improving the operation of punch tools and made those workers known as "slow hands" into "quick hands," increasing in average, the efficiency of production by more then 50 percents. The research on the rhythmical movement of operations which are involved in the assembling of electronic tubes not only reduced the work intensity of the workers but also raised production by more than 50 percents.

To meet the great demand for speedy training of technical workers as a result of the "big-leap" in production, our psychologists conducted some researches in this area also. In conformity with the national undertaking of increasing steel production, they proceeded to study how to master to judge the condition of the converter flame - which is one of the important techniques of steel workers operating the converter. Combining old workers' experiences in flame judgments, theories of steel production with converters and principles of visual psychology, the psychologists found out the conditions for changes in color, intensity, and form, etc. of the frames and the sparks emitted by the converter and the relationship between the temperature and chemical reactions inside the converter. Out of these findings, they edited instruction materials, and helped factories in the training of apprentices; they also made the workers master more quickly and effectively the technique of judging the conditions in the process of making steel through observations of the characteristics of the flames.

In regard to textile industry, psychologists dealt with the problems of training fine textile weavers in the technique of connecting threads. They investigated the effects of the preassigned goal-index of tasks on the workers' learning, and methods of correcting wrong movements as well as the importance of kinaethetic sensations in learning skills, and suggested the method of a combined training in the technique of connecting threads,and "thread-pul ling" movements. This new method curtailed more than half of the training time.

Besides, keeping in line with the technical innovation movement which was spreading over our country, our psychologists studied ways of promoting creativeness and inventiveness. They applied the principles of association and the method of utilizing frototypes for the provocation of creative thinking. Helping in the mass movement in the punch shop, they enabled the workers to create more than one hundred types of automatic punches. Some workers invented "electric conducting plate counter" by using an automatic punch as the prototype, thereby eliminating hand operations and twice increasing work efficiency. In another factory, the psychologists used the same method which also stimulated workers in creating quite a number of automatic punches in their spare time. With these studies, they entered the first stage of investigations into the characteristics and the true nature of creative thinking as well as the role in creative and inventive work played by the prototype, knowledge and techniques in special fields. They regarded crearive thinking as an activity reflecting the objective laws. Therefore, in their opinion, once one understands how to apply these laws, creation and invention can be achieved with proper aims and plans and good or- 
ganizations. The fact obtained in these fruitful studies of Chinese psychologists made short work of the phoney Idealistic theory of Capitalist psychology which holds that creations and inventions are invoked by accidental "inspiration" of a few "geniuses."

While making every effort to raise the productive rate of labor, Socialist countries put special stress on the necessity of guaranteeing production safety. In this respect, Chinese psychologists studied the cause of accidents which happened in industrial and mining works and investigated ways of prevention.

Medical Psychology. The Chinese Communist Party and the People's Government always regard man as the most precious wealth of the country, and thus are concerned very much for the people's health. They have been trying all means to fight against all sorts of diseases (including mental diseases) which have dangerous effects on people's health. Being one of the weapons for prophylaxis, medical psychology also received plenty of attentions. Moreover, the "big-leap" in medical work gave rise to many new demands for the development of medical psychology. Chinese psychologists began to cooperate closely with medical workers in their common efforts to prevent diseases and protect people's health.

One of the main tasks already started was the study on psychological problems in the prophylaxis of neurasthenia. Since the Liberation, this kind of study had been continued off and on, though in the earlier period, the effects of the treatment of neurasthenia by the psychological and medical workers were very little. They were still unable to free themselves from the old idea that neurasthenia is a chronical disease not easy to cure. Since the "bigleap" of 1958, the tremendous accomplishments obtained by the whole nation in all aspects of Reconstruction work inspired the medical and psychological workers to break away from old ideas. Summarizing the past experiences in the treatment of neurasthenia, they now regard neurasthenia as a mental disease to which a thorough application of psychotherapy throughout the treatment is indispensable. Furthermore, they are of the opinion that in order to improve the functional state of the patient's cerebral cortex, it is necessary to make use of the synthetic method of treatment including psychotherapy, medical treatment and physical therapy.

Also in our psychologists' opinion in Socialistic countries, all medical doctors and psychological workers as well as patients have the Communist spirit of cooperation to a high degree and their relationships are those of comrades, so that it is possible for their respective roles to get coordinated and for the subjective activeness to become manifest through mutual influences. Besides they have all other favorable conditions for the therapy (e.g. medicines and favorable environment, etc.) as well. Under these circumstances, this kind of disease could therefore be overcome within a short period.

In accordance with this viewpoint, the medical psychologists applied the quick synthetic method of treatment, of which collective psychotherapy is an essential part, to university and college students, steel and iron workers and patients in hospitals. With the patients continuing at their daily work and studies, they obtained highly effective results after 4 weeks of treatment. Of all the patients treated, over 50 percents completely recovered (including basically recovered ones), and near 30 percents were evidently improved. From these treatments, medical psychologists began to investigate one of the main clinical methods of psycho- 
therapy which, at present, is frequently used - i.e. the explanatory method of therapy.

Based on experiences obtained during practice, medical psychologists considered the main contents of psychotherapy as consisting of the following three aspects: (1) To introduce to patients the knowledge relative to neurasthenia, to eliminate their worries about the disease, and to call forth and reinforce their belief in the effectiveness of the short-course treatment. (2) To encourage patients to fight actively against the disease, to teach them the concrete means with which they could actively overcome the disease, and to fully develop the role of patients' subjective activeness. (3) To consider each patient's case history of the disease, and help him analyze and change his incorrect understanding of the situation which led to the formation of the disease, building up the correct attitude toward the disease. It is the belief of the medical psychologists that the functions of psychotherapy, medical treatment and physical therapy are usually complementary. Psychotherapy may play a greater role in breaking the vicious circle of the disease, in elevating the tension of cortical activities, and also in dealing with causes of the disease. Besides, medical psychologists examined the causes of the disease during the treatment.

Psychological researches on the prophylaxis of neurasthenia are still being carried on. Medical psychologists are making a further study of the mechanisms underlying the formation of the disease and its cure, with a mind to finding an effective therapy.

To the higher nervous activity of psychotics close attention was paid by Chinese medical workers, especially by the psychiatric workers. With psychotics and neurotics, they used the method of conditioned motor reflex with verbal reinforcements as well as the method of electro-encephalography and galvanic skin reflex recordings respectively in investigating the formation, the extinction, and the reformation of conditioned reflexes, and the mutual transposition of the two kinds of signal systems. They studied some emotional reactions of the patients and the type characteristics of schizophrenia as well as the effects of the environment on the occurrence of the disease by analyzing the patients' case history and clinical observations.

In the classical medical work of China, there have been theories and experiences concerning the role of psychological factors in the onset of illness, its diagnosis and treatment. This fact already received the full attention of medical workers and medical psychologists, and these classical theories and experiences are now being uncovered and studied, and also applied in the practice.

The above is a brief summary of psychological research work in connection with practice, which was carried out in recent years. One can see that, Chinese psychologists have already taken the first step in making psychology serve Socialist Reconstruction. Since the "big-leap" of 1958, the tasks of psychology as demanded by Socialist Reconstruction have been becoming more and more. For instance, athletes and artists are incessantly asking psychologists for their assistance. They already made investigations into some of their problems, but more problems are left untouched. The general situation indicates that their work is still far from being able to satisfy the demands of Socialist Reconstruction. This situation made Chinese psychological workers feel their great importance and tremendous responsibility in the Socialist Reconstruction of their fatherland. From now on, Chinese psycho- 
logists should, on the one hand, continue to connect their studies even further with practical work. This is the main direction of the present research work in Chinese psychology. On the other hand, they also have to put more emphasis on the theoretical problems in psychology. The preliminary experimental studies on fundamental theories which were undertaken by Chinese psychologists in the early period of the building up of Marxian psychology are to be continued, and extended.

It should be noted again that the theoretical studies carried out by the Chinese psychologists thus far are far from the demand of the society, and so should be greatly increased from now on. The practical experiences of the recent period have proved that only by raising the level of one's theoretical knowledge could one solve even greater problems in the practice of Socialist Reconstruction. All these months, Chinese psychological workers have been intensively debating and discussing some fundamental problems concerning the tasks, the subject matter, and methods of psychology. They have obtained a clearer understanding of these problems through the debates and discussions the results of which would be beneficial to their future work. Moreover, Chinese psychologists have realized that, in future work, regardless of whether it be theoretical or practical, one must pay full attention to the application of advanced scientific techniques to psychology.

Finally, in their opinion, due to the highly complex nature of psychological phenomena. they should apply all sorts of methods in research and make investigations from all angles, while holding to the materialist interpretation of psychological phenomena as well as the objective principles in methodology. Only in such a way, one can expect a better solution of the problems and a speedy advance of psychological science. The traditional methods in psychological studies are, of course, still needed, but by no means can one be justified in neglecting the application of new techniques and new theories. On conclusion, the Chinese psychologists believe that Chinese psychology has a broad and promising outlook, and that its contribution to Socialist Reconstruction will be greater and greater. Chinese psychologists are making all attempts to accelerate the establishment and the development of psychological science so as to be ready to meet the demands of the Socialist future.

MS. received IX 22, 59.

Pan Shuh（潘菽 1897-） Ph. D. Univ. of Chicago. Director, Institute of Psychology, Academia Sinica, Peking; President, Chinese Psychol. Assoc.

\section{CONTENTS OF ACTA PSYCHOLOGICA SINICA}

Vol. I, No. 1 1956, November.

* Pan, Shuh (潘菽). Concentrate the forces of the group to the fight for the development of the scientific psychology which serves the great socialistic construction of Our Country. 1-10.

* Chu, Chih-shien (朱智賢). Problems on the object of psychology. 11-19.

* Tsang, Yü-hai(藏玉海) . Some important problems on the object of psychology. 20-26

* Pan, Shuh (潘菽). Comments on the philosophical problems on psychology. 27-34. $\star \star$ Yeh, Ling (葉屡). L'activité mentale de l'homme, est-elle son activité nerveuse superieure? 35-45.

* Ching, Chi-cheng (荊其誠)，\& Yeh, Hsüan (葉絢). A fundamental critique of the idealistic sense physiopsychology. 47-57.

* Tsao, Jih-chang (曹日昌). Problem of excitation process. 59-69.

+ Shen, N. C. (沈輏幥), Shao, C. (邵郊), \& Shen, T. T. (沈徳衬). The relationship between the frequency of electrical current and the motor 
effect when the dog's sigmoid gyrus is under direct electrical stimulation. 71-83.

* Liu, Fan (劉笔) Peng. Jui-hsiang (彭喘辛) Li, Mei-ko (李美格), \& Hsu, Lien-tsang (徐联會) The effect of the alternate differentiation method of near and far differential agents on the formation of differential inhibition. 84-94.

* Li, Chia-chih (李家治), Ho, Pao-yuan(赫荣源), \& Chao, Pi-ju (趙塈如). Response to stimulus sequence in the dynamic motor stereotype. 95-105.

Vol. I, No. 2 1957, December.

*+Chen, Li (陳立), \& Tsao, Jih-chang (曹日昌). Industrial psychology in the German Democratic Republic. 107-116.

ネ+ Woo, Chiang-lin (員江霖), et al. An experimental study of the interaction of the first and second signal systems. 117-133.

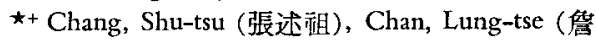
龍澤), \& Shen, Te-li (沈德立). The effect of words in children's generalized cognitions. 134142.

*+ Tsao, Jih-chang (曹日昌), Ching, Chi-cheng (荊其誠)，\& Lin, Chung-hsien (林仲賢). Preliminary studies on prediction of motion. 143-157

$\star \star$ Ching, Chi-cheng (荊其誠), \& Yeh, Hsüan(葉 私). Experimental studies on the thresholds of visual movement. 158-164.

*+ Chiba, Y. (千葉康則), Fusui, W. (巫水綿)，\& Tanaka, M. (田中守野). A study of time conditioned reflex. 165-175.

*+ Liu, Fan (劉範). Some facts about the interaction of the cerebral hemispheres of the dog. 176183

*+ Li, Chia-chih (李家治), \& Hsu, Lien-tsang (徐 联倉). A preliminary analysis of the causation of industrial accidents. 184-193.

*+ Ni, Chung-fan (倪中方). A preliminary criticism on the behaviorism of J. B. Watson. 194-200

Vol. I, No, 1 1958, July.

A note in commemoration of Sun, Kuo-hua(孫 国華) 1-2.

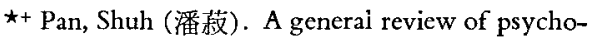
logy in China. 3-9.

$\star+$ Luria, A. R. The function of language in the formation of psychological process. 10-25.

*+ Pan, Shuh (潘菽). A general review of psychology in German Democratic Republic. 26-35,

*+ Woo, Chiang-lin (員江霖). Research work on psychology of personality in the German Democratic Republic. 36-45

$\star+$ Lun, Shu-hsiu (能叔修). Researches in perception in Democratic Germany. 46-52.
*+ Hsu, Shu-lien(萍淑逨)，\& K'uang P'ei-tzu(匡 培样). Note on types characterized by the coupling of the highest nervous activity in children by means of verbally reinforced motor conditioning method. 53-64.

*+Yeh, Hsüan (荣絢), \& Fang, Yün-chiu(方芸秋). A preliminary experimental study in spatial orientation of preschool children. 65-71.

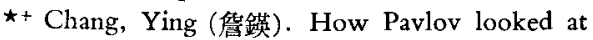
psychic activity and psychology. 72-84.

*+ Chu, Hsi-liang (朱希亮). Critical comments on gestalt psychology. 85-98.

\section{9, No. 1, June.}

Tsao, Jih-chang (曹日啰). Some problems in psychological research. 1-6.

Chu, Chih-shien (朱智賢). On the class nature of human mind. 7-16.

Tsao, Chuan-yung (曹傳詠). Is psychology to study the activities of human brain? 17-21.

Chang, Chih-kuang (章志光). Further comments on the subject matter and nature of psychology. 22-31.

$\mathrm{Wu}$, Shu-chien (唤書柬). Notes on universal laws of human psychological activities. 32-35.

$\star+$ Division of industrial psychology, Institute of Psychology, Academia Sinica. Some psychological problems in attempt at promotion of invention and creation. 36-41.

*+ Chen, Li (陳立), \& Chu, Tso-jen (朱作仁). Some psychological problems in the training of fine textile weavers. $42-50$.

$\star \star$ Division of industrial psychology, Inst. of Psychol., Academia Sinica. A preliminary study in methods for improving operations on punch. 51-56.

Book Review:

Cheng, Nai-i(程逎䫀). Ching, Chi-cheng's (荊 其誠) “Theoretical Foundations of Structualism in Wundt's and Titchener's Works." 57-58. Events in Science:

Panel discussion on psychological problems held by the Institute of Psychology, Academia Sinica, and some other institutions. 59-60.

Discussions on the psychological problems by the instructors and students of education department, South-western Normal College. 60-61. In other countries:

Some difficulties in the development of Polish psychology and the work of Polish psychologists (Abbreviated translation). 62-64.

1959, No. 2, July.

Kuo I-chen (郭一婜). Concerning the scientific nature of psychology. 65-75. 
Cheng, Nai-i (程迺臨). On the subject matter of psychology. 76-82.

Peng, Fei (彭飛). The problems of the relation between "psychological form and content." $83-88$ Chen, Kuo-mei (梪㵵眉). Several comments on the subject matter, tasks and methods of psychology. 89-95.

Chen, Ta-jou (陳大柔). The tasks of psychology from a practical viewpoint. 96-99.

Chang, Hou-chan (張厚婪). On the subject matter of psychology. 100-108.

*+ Division of industrial psychology, Institute of Psychology, Academia Sinica. Creative thinking as observed in constructing automatic punching and die machinery. 109-116.

${ }^{\star}+\mathrm{Lu}$, Chung-heng (盧仲衡), \& Ma, Li-ying (馬 利英). Studies on certain rules of abbreviations and variations in the project of Romanizing Chinese spelling system. 117-126.

Events in psychological science;

Problems of the basic theories of psychology discussed by the psychological workers of ChiangSu Provience. 127-128.

Debates on the nature of psychology and other problems by members of An-Hui Normal College. 128-129,

Theoretical problems of psychology in the realization of class struggles: A discussion by the psychological workers of Hsi-An. 129

In other countries;

Remarks on the Rumanian psychology(Abbreviated translation). 130-132.

1959 No. 3 (Total No. 6) August.

Pan, Shuh (潘菽). The position of psychology in the system of science. 133-136.

Tsao, Jih-chang (曹日昌). Debates in psychology. 136-141.

Chen, Da-jou (陳大柔). How psychology can be of service to the socialistic reconstruction. 142-145.

*+ Ting, Tsan (丁瓚). How to develop medical psychology in China. 146-150.

$\star+$ Division of Medical Psychology, Inst. of Psychol. Academia Sinica. Function of psychotherapy in a speedy and synthetic treatment of neurasthenia. 151-160.

$\star+$ Division of Industrial Psychology, Inst. of Psychol., Academia Sinica. A preliminary study on the visual judgement of flames by the steel workers operating the converters. 161-167.

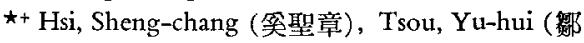

玉慧), \& Lin, Chung-hsien(林仲賢). An experimental study on observations of stimuli from different directions. 168-177.

$\star+W u$, Chin-eh (䣓勤娥). Conditioned reflex in simultaneous discrimination of figures in dog. 178-182.

Events in Psychological Science

Discussion of psychological problems by the psychological circles in Peking. 183-185.

Discussion of some theoretical problems of psychology by the teaching faculties of the Dept. of Educ. Ho Fei Normal College 185-186.

Symposium for the psychological problems by scientific workers of the Institute of Education, Shan Tung Branch, Academia Sinica. 186.

In other counties

The contribution of Austrian scientists to the theory of perception (Abbrev. transl.). 187-189.

1959, No. 4 (Total No. 7) September.

*+ Pan, Shuh (潘菽), \& Chen, Da-jou (陳大柔). Ten years' developments in Chinese psychology. 191-203.

*+ Tsao, Jih-chang (曹日昌), \& Li, Chia-chih (李 家治). Industrial psychology in China. 204-214.

*+ Lung, Shu-hsiu (龍叔修), \& Liu, Fan (劉範). Studies in psychological processes and their physiological mechanism. 215-226.

Pan, Shuh (潘菽). On the subject matter of psychology and related problems. 227-233.

Tan, Yueh (唐鐡). On the subject matter of psychological study. 234-236.

Chu, Chih-hsien (朱智賢). Some viewpoints concerning the subject matter of psychology. 237-243.

Tsao, Jih-chang (曹日昌). What does psychology investigate? 244-249.

Liu, Fan (劉範). Preliminary viewpoints regarding the subject matter of psychology. 250-255.

*+ Division of Medical Psychology, Inst. of Psychol., Academia Sinica. A summary of practice in speedy-synthetic treatments of neurasthenics among the steel workers. 256-263.

Sun, Yeh (孫睟). A review of literatures on criticisms of Freudian psychoanalysis. 264-270.

Events in Psychological Science

Symposium held by the psychological circles of Inner Mongolia, Hei Lung-chiang, Hunan, Hupt i, and Shanhsi. 271-275

In other countries

Hsu, Lian-tsang (徐联會). What are Soviet psychologists studying? 276-278.

With abstracts in Russian( $\left(^{\star}\right)$, English( $\left(^{+}\right)$, French( $(\star \star)$, Russian and English( $\left.{ }^{\star+}\right)$. Russian and German( $\left(^{\star \star}\right)$. 